\title{
Exploring the Perceived Barriers and Benefits of Physical Activity Among Wounded, Injured, and/or Sick Military Veterans
}

\author{
Robert Walker, MSc \\ School of Sport and Health Sciences, Cardiff Metropolitan University, Cardiff, Wales \\ Caroline Limbert, $\mathrm{PhD}$ \\ School of Sport and Health Sciences, Cardiff Metropolitan University, Cardiff, Wales \\ Paul M. Smith, PhD \\ School of Sport and Health Sciences, Cardiff Metropolitan University, Cardiff, Wales
}

Contact: rwalker@cardiffmet.ac.uk

\begin{abstract}
Wounded, injured, and/or sick (WIS) military veterans face significant physical and psychosocial challenges following discharge from service. Physical activity can have many positive effects on the holistic wellbeing of such individuals. However, little knowledge exists regarding the perceived barriers and benefits of physical activity within this population, creating challenges surrounding physical activity promotion. Therefore, this study was designed to identify key barriers and benefits among this population, so that informed approaches to encourage participation in physical activity can be developed. A questionnaire related to the perceived barriers and benefits of physical activity was completed by 105 WIS British military veterans. Participants were predominantly male, physically active, served in the British Army, and described their injury as frequently impacting their daily living. Factor analysis revealed that poor mental health, negative beliefs about physical activity, and low beliefs about physical capability were prominent barriers represented in the data. However, only veterans' beliefs about their physical capability were related to physical activity levels and differed between active and insufficiently active participants. Beliefs identified as benefits of physical activity that correlated with physical activity levels were improved mental and physical health, a sense of purpose, and increased physical fitness. Subsequently, barriers and benefits were categorized using the Behaviour Change Wheel, a behavior change framework, that indicated intervention functions of education, incentivization, and persuasion might be effective methods of increasing physical activity behavior among WIS veterans. Ultimately, this will lead to greater engagement with physical activity and improved health and wellbeing within this population.
\end{abstract}

Keywords: Behaviour Change Wheel; Health; Exercise; Sport; Military.

Date Submitted: October 31, 2020 | Date Published: June 2, 2021

\section{Recommended Citation}

Walker, R., Limbert, C., \& Smith, P. M. (2021). Exploring the perceived barriers and benefits of physical activity among wounded, injured, and/or sick military veterans. Journal of Social, Behavioral, and Health Sciences, 15, 141163. https://doi.org/10.5590/JSBHS.2021.15.1.11 
Walker et al., 2021

\section{Introduction}

\section{Literature Review}

Physically wounded, injured, and/or sick (WIS) veterans face significant challenges following injury or illness. Not limited to the physical challenge of adapting to life with a significant injury or illness, WIS veterans may be susceptible to developing mental health disorders, such as post-traumatic stress (Fulton et al., 2015; Williamson et al., 2019). Injury or illness can often lead to medical discharge from military service and this will necessitate an individual adjustment to a new culture and environment. Researchers have suggested that prominent differences between military and civilian cultures can result in a lack of cultural competence in the civilian world (Cooper et al., 2017, 2018). For example, skills highly revered in military culture, which often lead to promotion and career advancement, do not necessarily carry a similar value in the civilian world. Therefore, it is not surprising that, when linked to a diminished health status, veterans with physical health conditions struggle more with adjusting to the civilian world than their physically healthy veteran peers (MacLean et al., 2014). Researchers have identified that veterans with service-connected conditions and who suffer from PTSD or major depression often die prematurely due to suicide, accidents, or an assault (Maynard et al., 2018), which emphasizes the need for preventative interventions associated with ongoing health care.

Researchers and practitioners are increasingly using physical activity as a method of improving the holistic wellbeing of veterans (Brittain \& Green, 2012). Scoping and systematic reviews have demonstrated that physical activity can have a range of positive effects on the psychosocial wellbeing of WIS veterans who are suffering from mental health conditions (Walker, Smith, et al., 2020), veterans/service personnel who are ill or injured (Shirazipour, Tennant, et al., 2019) and combat veterans (Caddick \& Smith, 2014). Researchers have investigated veterans with physical disabilities for experiences and ideal outcomes of quality physical activity and program strategies that facilitate it (Shirazipour et al., 2017; Shirazipour, Aiken, et al., 2018, 2019: Shirazipour \& Latimer-Cheung, 2020). However, despite this, little research exists relating to the physical activity behavior of WIS military veterans.

Perceived barriers to and facilitators of physical activity have been explored among some populations of veterans; for example, veterans with lower limb loss (Littman et al., 2014, 2017), veterans with a physical disability (Shirazipour et al., 2017), and post-operational deployment veterans (Buis et al., 2011). Researchers identified a range of perceived barriers and facilitators of physical activity, mostly utilizing qualitative methodologies. Similarly, only qualitative research has been conducted in this area with WIS veterans (Walker, Colclough, et al. 2020); that is, those who are experiencing some form of physical wound, injury, and/or sickness that adversely impacts their daily living to some extent. Numerous UK-based military charities and their physical activity interventions target WIS veterans; thus, there exists a need to analyze behavior in this broader population of veterans.

In their qualitative investigation of physical activity behavior among WIS veterans, Walker, Colclough, et al. (2020) identified a range of perceived barriers to and benefits of physical activity. Findings provided rich, qualitative data that shed important light on this underrepresented population. However, as notable in similar research studies (Littman et al., 2017), employing qualitative methodologies makes it difficult to generalize findings associated with relationships between physical activity behavior and perceived barriers and benefits. Moreover, Walker, Colclough, et al. (2020) suggested that their findings would benefit from further quantitative analyses to identify potential latent constructs within their data. Therefore, the current study built upon the findings of Walker, Colclough, et al. (2020) to provide information relating to possible latent constructs present within the qualitative data and relationships linked with physical activity. In doing so, an improved understanding related to the perceived barriers and benefits among WIS veterans and their explicit associations with physical activity can be gained, creating a more generalizable understanding. 


\section{Objectives}

This study had three objectives:

1. To build upon the findings reported by Walker, Colclough, et al. (2020) by designing and distributing a questionnaire to explore perceived barriers and benefits of physical activity among a larger sample of WIS British military veterans;

2. To compare perceived barriers and benefits of physical activity to self-reported levels of physical activity and other participant demographics to highlight key participation barriers and benefits; and

3. To use the Behaviour Change Wheel, a framework of explaining behavior change, to categorize barriers and benefits of physical activity and create practical recommendations for the development of physical activity behavior change interventions.

\section{Study Framework}

Behavior change researchers and practitioners often stress the importance of a systematic approach to behavior change that is specific in its target population and underpinned by the development of relevant theory (Michie et al., 2014; O'Cathain et al., 2019). However, it has been estimated that only 22.5\% of implementation studies have been found to draw upon theories of behavior change (Davies et al., 2010), emphasizing the importance of analyzing the physical activity behavior of WIS veterans through a framework of behavior change.

The Behaviour Change Wheel (BCW) and its associated capability, opportunity, motivation-behavior (COMB) model (Michie et al., 2011, 2014) provide a comprehensive framework for evaluating behavior and eliciting behavior change. It has been applied in many behavioral fields, including physical activity (Munir et al., 2018; Seppälä et al., 2018; Taylor et al., 2013; Walker, Colclough, et al., 2020).

As seen in Figure 1, the center of the BCW diagram illustrates the COM-B model. Capability refers to one's perceived ability to engage in a particular behavior; opportunity reflects the external factors that influence behavior; and motivation conceptualizes brain processes that energize and direct behavior. As seen in Figure 2, capability, opportunity, and motivation are interrelated and have a reciprocal relationship with behavior.

The second (yellow) ring of the BCW is the theoretical domains framework (TDF) which has been mapped to the BCW (Cane et al., 2012). The TDF was originally designed to provide an extensive, evidence-based approach to identifying determinants of behavior, 14 of which have been integrated with the COM-B model.

Intervention functions, which researchers and practitioners can use to aid the design of behavioral interventions, are located within the penultimate (red) ring of the BCW. In contrast, policy categories, related to the delivery of interventions, exist in the outermost ring. The BCW was adopted in the current study as a comprehensive framework of the interrelated processes of behavior change that is translatable across scientific and non-scientific disciplines. 


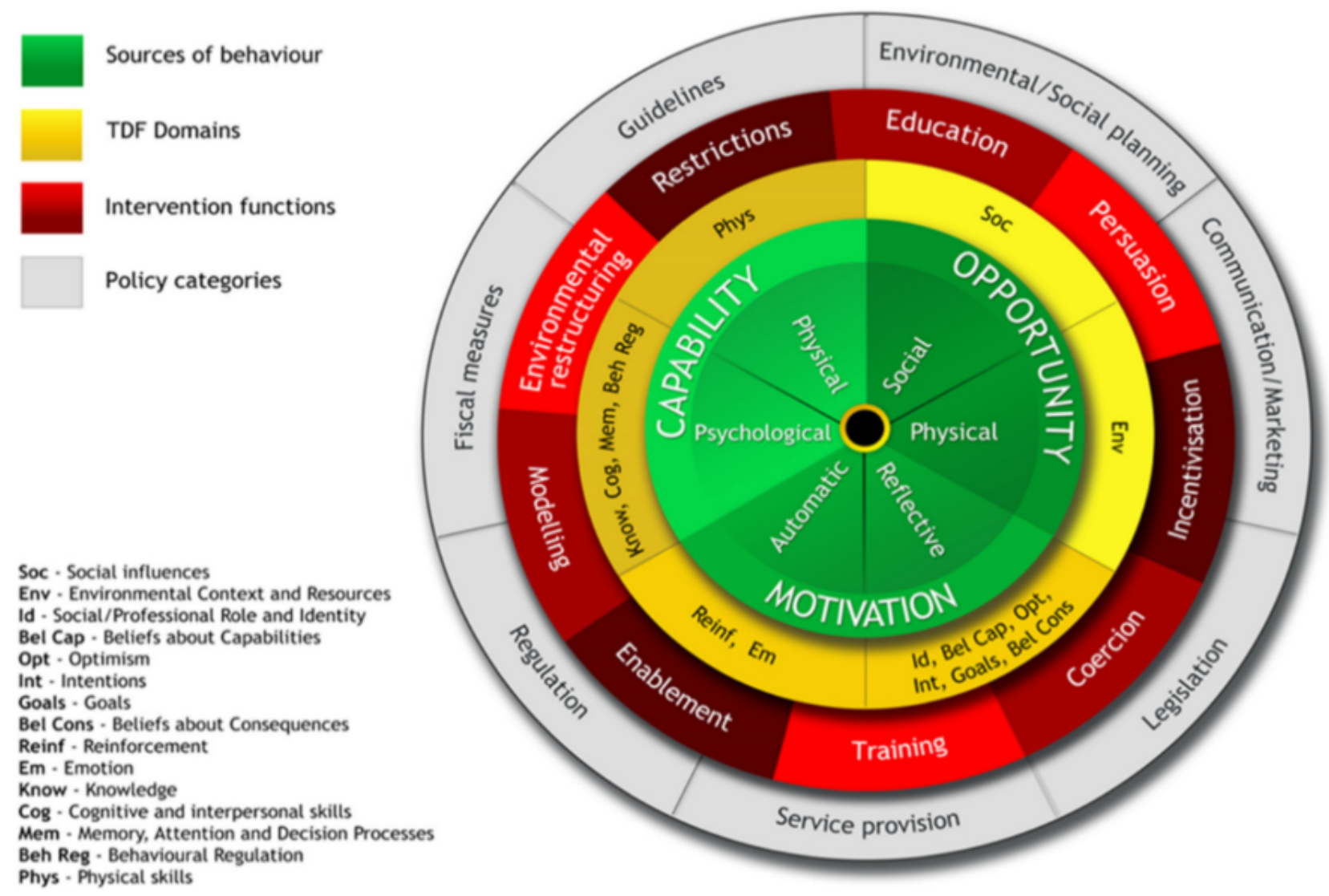

Figure 1: The Behaviour Change Wheel (BCW) With Adapted Theoretical Domains Framework (TDF) Ring

Note. From The Behaviour Change Wheel: A Guide to Designing Interventions, by S. Michie, L. Atkins, and R. West, 2011, Silverback Publishing. www.behaviourchangewheel.com. Reprinted with persmission.

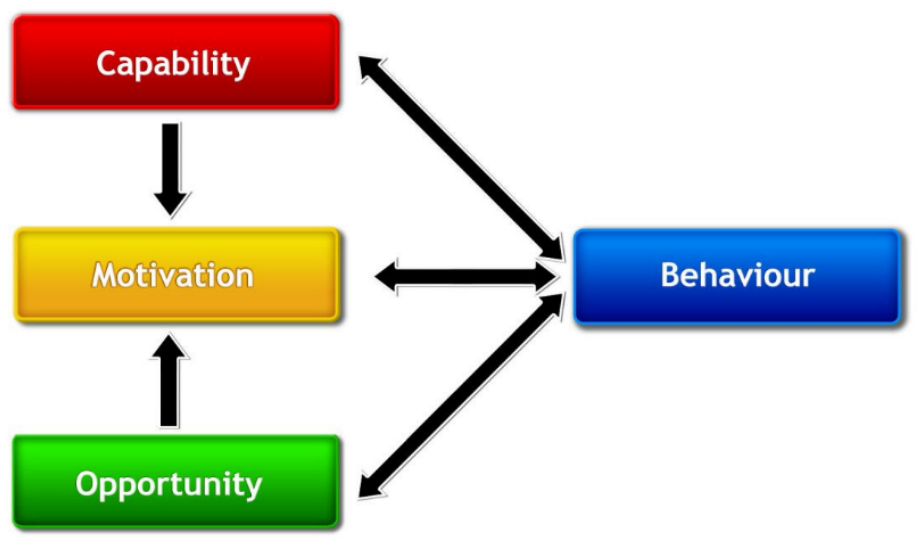

Figure 2: Capability, Opportunity, Motivation-Behaviour (COM-B) Model

Note. From The Behaviour Change Wheel: A Guide to Designing Interventions, by S. Michie, L. Atkins, and R. West, 2011, Silverback Publishing. www.behaviourchangewheel.com. Reprinted with persmission. 


\section{Methods}

\section{Participants}

Completed questionnaire responses were received from 105 WIS military veterans. A power analysis calculation for this study was conducted using the software $G^{*}$ Power 3 (Version 3.1; Faul et al., 2007). Based upon a medium effect size, a total sample size of 220 was required to avoid type I or type II statistical errors. However, due to the specificity of the target population, the researchers were not able to recruit the required sample size.

The age of participants ranged from 27 to 79 years $(M=51.88, S D=9.81)$, with rank at time of discharge from service ranging from the lowest (Private, Able Rate, Aircraftman) to senior officers (Lieutenant Colonel, Commander, Wing Commander). Summary information relating to participants' demographics can be found in Table 1.

Table 1: Participant Demographic Information

\begin{tabular}{|c|c|c|c|}
\hline Sample & $\mathrm{N}=105$ & & \\
\hline & & $\mathrm{N}$ & $\%$ \\
\hline Gender & Male & 80 & 76.2 \\
\hline & Female & 25 & 23.8 \\
\hline Godin-Shepard Leisure-Time & Active & 56 & $53 \cdot 3$ \\
\hline & Moderately active & 17 & 16.2 \\
\hline & Sedentary & 32 & 30.5 \\
\hline Service & Army & 77 & $73 \cdot 3$ \\
\hline & Royal Navy & 11 & 10.5 \\
\hline & Royal Air Force & 17 & 16.2 \\
\hline Length of Service & $<4$ years & 5 & 4.8 \\
\hline & $4-8$ years & 25 & 23.8 \\
\hline & $9-12$ years & 22 & 21 \\
\hline & $13-16$ years & 14 & $13 \cdot 3$ \\
\hline & $17-20$ years & 11 & 10.5 \\
\hline & $21+$ years & 28 & 26.7 \\
\hline Rank & Non-commissioned officer/junior rank & 93 & 88.5 \\
\hline & Commissioned officer & 12 & 11.5 \\
\hline Daily Impact of Injury & Frequently & 82 & 78.1 \\
\hline & Somewhat frequently & 19 & 18.1 \\
\hline & Infrequently & 3 & 2.9 \\
\hline & No response & 1 & 0.9 \\
\hline Requires a Caregiver & Full-time & 15 & 14.3 \\
\hline & Part-time & 11 & 10.5 \\
\hline & No & 78 & 74.3 \\
\hline & No response & 1 & 0.9 \\
\hline Mental Health Condition & Yes & 85 & 81 \\
\hline & No & 20 & 19 \\
\hline Mental Health Condition Types & Post-traumatic stress disorder & 47 & 44.8 \\
\hline & Depression & 60 & 57.1 \\
\hline & Anxiety & 57 & $54 \cdot 3$ \\
\hline
\end{tabular}




\begin{tabular}{|c|c|c|c|}
\hline \multirow[t]{5}{*}{ Place of Birth } & United Kingdom & 100 & 95.2 \\
\hline & Bahrain & 1 & 1 \\
\hline & Germany & 2 & 1.9 \\
\hline & Iraq & 1 & 1 \\
\hline & Ireland & 1 & 1 \\
\hline \multirow[t]{5}{*}{ Country of Residence } & England & 58 & 55.2 \\
\hline & Wales & 31 & 29.5 \\
\hline & Scotland & 11 & 10.5 \\
\hline & Northern Ireland & 3 & 2.9 \\
\hline & Germany & 2 & 1.9 \\
\hline \multirow[t]{4}{*}{ Highest Level of Education } & Secondary School & 34 & 32.4 \\
\hline & College/sixth form & 39 & 37.1 \\
\hline & University Undergraduate & 19 & 18.1 \\
\hline & University postgraduate & 13 & 12.4 \\
\hline \multirow[t]{5}{*}{ Employment Status } & Full-time employment/education & 41 & 39 \\
\hline & Part-time employment/education & 13 & 12.4 \\
\hline & Unemployed & 24 & 22.9 \\
\hline & Retired & 26 & 24.8 \\
\hline & No response & 1 & 0.9 \\
\hline \multirow[t]{9}{*}{ Annual Income } & $£ 0-£_{10,000}$ & 19 & 18.1 \\
\hline & $£ 10,000-£ 20,000$ & 35 & $33 \cdot 3$ \\
\hline & $£ 20,000-£ 30,000$ & 20 & 19 \\
\hline & $£_{30,000-£ 40,000}$ & 9 & 8.6 \\
\hline & $£ 40,000-£ 50,000$ & 13 & 12.4 \\
\hline & $£ 50,000-£ 60,000$ & 3 & 2.9 \\
\hline & $£ 60,000-£ 70,000$ & 1 & 0.9 \\
\hline & $£ 70,000+$ & 2 & 1.9 \\
\hline & No response & 3 & 2.9 \\
\hline
\end{tabular}

WIS British military veterans were recruited using mailing lists provided by Help for Heroes, a prominent British military charity and social media pages of several independent British military veterans' groups. Within a specific advert, researchers provided detailed information about the study, alongside a sharable hyperlink, which directed participants to an online survey. This approach was applied on a bimonthly basis, for 3 consecutive months, after which time data collection was closed.

The British Government's definition of a military veteran was applied as "anyone who has served for at least one day in Her Majesty's Armed Forces (Regular or Reserve) or Merchant Mariners who have seen duty on legally defined military operations" (Ministry of Defense, 2017). The research team conceptualized WIS veterans as, "A veteran who has experienced a physical injury and/or illness that was gained either during or after military service and which influences their daily living." However, veterans who had a serious mental illness (SMI) were excluded from the study. Other mental illnesses, such as post-traumatic stress disorder (PTSD), were identified as likely co-morbidities of traumatic physical injury and military service, so participants with these characteristics were not excluded. To ensure that participants were within the target population and met inclusion/exclusion criteria, a series of screening questions were included prior to data collection and analysis. Ethical approval was obtained from the School of Sport Ethics Committee, Cardiff Metropolitan University. Project reference number: PGR-1300. 


\section{Measurement Tools}

Measurement tools were uploaded online via the survey software Qualtrics (January 2020 version). Measures were related to participant demographics, perceived barriers to and benefits of physical activity, and current levels of physical activity.

Perceived barriers to and benefits of physical activity questionnaire. A questionnaire was created and distributed to assess the perceived barriers to and benefits of physical activity among WIS veterans. We developed questions using the thematic analysis of semi-structured interview data with the BCW as a guiding framework (Walker, Colclough, et al., 2020). The research team decided which themes previously identified by Walker, Colclough, et al. (2020) would be included based upon their perceived value and the quality of information that would likely stem from them. However, as questionnaire response fatigue was a likely barrier to participant recruitment, only prominent themes were included. Selected themes included in the questionnaire can be seen in Table 2. Each theme was included using three related, but differently worded, items so that reliability could be evaluated post-data collection.

Table 2: Selected Perceived Barriers to and Benefits of Physical Activity Questionnaire Themes

\begin{tabular}{|l|l|}
\hline Selected perceived barrier themes & Selected perceived benefit themes \\
\hline - Lack of interest in organized activities & $\bullet \quad$ Improved physical fitness \\
- Lack of awareness of physical activity & - Increased confidence \\
- Financial circumstances & - Improved mental health \\
- Docation of activities & - Improved physical health \\
- Dislike of competitive activities & $\bullet \quad$ Opportunity to get out of the house \\
- Lack of time & - Feeling a sense of purpose \\
- Previous negative experience of physical activity & \\
- Lack of confidence in ability to do physical activity & \\
- Poor mental health & \\
- Poor physical health & \\
\hline
\end{tabular}

Based on these themes, a series of statements was designed using a 5-point Likert scale which asked participants to consider to what extent they either agreed or disagreed with each statement, with higher scores being associated with greater levels of agreement with the statement (i.e. 5 being strongly agree). Although 7-, 9-, and 10-point Likert scales have been suggested as statistically preferable (Preston \& Colman, 2000), a 5-point Likert scale was selected as previous research has considered that its implementation increases response quality and decreases frustration levels (Sachdev \& Verma, 2004). This was particularly significant for the current study as WIS veterans may suffer from poor mental health and, therefore, ensuring the questionnaire was as simple to complete as possible was important to maximize response quality and quantity. Five-point Likert scales are widely used instruments for measuring opinions, attitudes, and beliefs that allow for a neutral response (DeVellis, 2017). Allowing a neutral response to questions was considered important, as participants may not have a particular opinion or experience related to a specific barrier or benefit. The inclusion of a midpoint has also shown that it can increase the reliability estimate of an instrument (Adelson \& McCoach, 2010).

Physical activity assessment questionnaire. The Godin-Shepard Leisure-Time Physical Activity Questionnaire (GSLTPAQ; Godin, 2011) was used to assess participants' self-reported physical activity levels. The GSLTPAQ was used due to its simplicity and former application in the context of physical activity-related research with military veterans (Goldstein et al., 2018; Littman, et al., 2014). Moreover, the GSLTPAQ has been shown to be reliable through comparisons with maximum oxygen consumption and body fat in adults (Godin \& Shephard, 1985) and more recently among persons with significant illness, with an ICC of .74, with a 95\% confidence interval from .69 to $.78(\mathrm{~F}(1,533)=3.74, \mathrm{p}=<.001)$ (Motl et al., 2014). The GSLTPAQ required 
participants to select the frequency with which they participate in light, moderate, and intense physical activity, giving participants examples for each type of activity. The frequencies were then weighted and a total score of physical activity levels calculated and identified as either sedentary, moderately active, or active.

\section{Data Analyses}

Data analyses were completed using IBM SPSS statistics software for Windows, version 24. Cronbach's coefficient alpha was used to ascertain reliability of the questionnaire items. Items were then either included or excluded, depending on their effect on questionnaire reliability. Average values of items comprising each theme were calculated. Newly developed questionnaires are likely to measure constructs that cannot be directly observed, otherwise known as latent variables (DeVellis, 2017). As the questionnaire design was based upon qualitative data, it was considered likely findings would represent unobserved latent variables or variables that represent the same underlying construct. For this reason, two separate exploratory factor analyses were used to identify latent variables of the perceived barriers to and the benefits of physical activity.

Following exploratory factor analysis, difference, correlation, and regression analyses were conducted on the subsequent factors or themes and demographic information or physical activity levels. As the data consisted entirely of Likert data, nonparametric tests were utilized. Statistical tests for difference included the MannWhitney U test and Kruskal-Wallis H test, whereas, the associational statistic consisted of Spearman's Rho. Statistical significance was determined as $p=\leq .05$.

As the sample of this study predominantly consisted of active individuals $(n=56)$, according to the GSLTPAQ, additional analyses were conducted involving only insufficiently active participants; that is, those who are categorized as moderately active or sedentary with a GSLTPAQ score of 23 or less $(n=49)$. These categories have been shown to reflect whether a person is meeting physical activity guidelines, including American and Canadian guidelines (Amireault \& Godin, 2015; Godin, 2011), which largely reflect the current UK guidelines of 150 minutes of moderate physical activity per week (Department of Health and Social Care, 2019). This ensured that the results were not biased towards those who were already participating in high levels of physical activity.

\section{Results}

Comparisons between key demographic variables and physical activity levels revealed two significant differences. Physical activity levels differed between branches of service (Army, Royal Navy, Royal Air Force; $H(2)=9.07, p=.011)$. Mean $( \pm \mathrm{SD})$ levels of physical activity among branch of service can be seen in Table 3 . In addition, participants who reported experiencing greater daily impact from their injury or illness participated in less physical activity $(H(2)=7.15, p=.028)$. However, gender, length of service, country of residence, caregiver requirement, education, rank, employment, self-reported PTSD, depression, and frequent anxiety did not differentiate between sedentary, moderately active, and active categories of self-reported physical activity levels.

Table 3: Mean $( \pm S D)$ Values of Godin-Shepard Leisure Time Physical Activity Questionnaire Total Scores for Branches of Service

\begin{tabular}{|l|l|}
\hline Branch of service & Physical activity levels M( \pm SD) \\
\hline Army & $40.01(34.6)^{*}$ \\
\hline Royal Navy & $18.27(17.4)$ \\
\hline Royal Air Force & $22.29(27.52)$ \\
\hline
\end{tabular}

Note. $0-13=$ sedentary. $14-23=$ moderately active. $24+=$ active. ${ }^{*}$ denotes difference $(p=\leq .05)$ compared to Royal Navy and Royal Air Force 
Walker et al., 2021

\section{Perceived Barriers}

Adequate reliability was determined for nine of 11 barriers included in the questionnaire (Cronbach's $\alpha=\geq .7$ ). Both "financial" and "lack of interest in physical activity" barriers were identified as having low reliability, .66 and .51 respectively. One of the three items constituting the financial barrier theme was removed to improve its reliability from .66 to .81 . However, all items were retained in the lack of interest in the physical activity barrier theme, as their removal did not improve reliability.

A principal axis factor analysis was conducted on the 11 themes related to the perceived barriers with oblique rotation (direct oblimin). The Kaiser-Meyer-Olkin (KMO) measure verified the sampling adequacy for the analysis, KMO = .73 ("middling" according to Hutcheson \& Sofroniou, 1999), and all KMO values for individual items were above .6, which is above the acceptable limit (Field, 2018). An initial analysis was run to obtain eigenvalues over Kaiser's criterion of 1 . Four factors had eigenvalues over 1 and in combination explained $66.83 \%$ of the variance. The scree plot also supported the extraction of four factors and Table 4 illustrates factor loadings after rotation. A factor loading criterion of .512 was used, as this is recommended for this study's sample size (Stevens, 2002). Factor three was discarded from further analysis as only one variable adequately loaded onto the factor $(\geq .512)$. The themes that clustered on the same factor suggest that factor 1 is poor mental health, factor 2 is negative beliefs about physical activity, and factor 4 is beliefs about physical capability. Factors 1 and 4 were considered reliable $(\alpha=\geq .71)$. However, factor 2 held low reliability $(\alpha=.51)$.

Comparing scores of the three factors, poor mental health, negative beliefs about physical activity, and beliefs about physical capability, revealed that female participants reported feeling more physically capable $(U=$ $3960, p=.04, \mathrm{r}=.21$ ). Insufficiently active participants reported beliefs that they were less physically capable of engaging in physical activity $(U=2257, p=<.001, r=.45)$ and held greater negative beliefs about physical activity $(U=2554, p=.008, r=.26)$.

Table 4: Factor Loadings of Perceived Barriers to Physical Activity Engagement

\begin{tabular}{|c|c|c|c|c|}
\hline & Factor & & & \\
\hline Variable & $\begin{array}{l}\text { Poor mental } \\
\text { health }\end{array}$ & $\begin{array}{l}\text { Negative beliefs } \\
\text { about physical } \\
\text { activity }\end{array}$ & Factor 3 & $\begin{array}{l}\text { Beliefs about } \\
\text { physical } \\
\text { capability }\end{array}$ \\
\hline Dislike of new environment & .795 & & & \\
\hline Poor mental health & .751 & & & \\
\hline Location & .572 & & & \\
\hline $\begin{array}{l}\text { Not interested in physical } \\
\text { activity }\end{array}$ & & .786 & & \\
\hline Dislike of competition & & .516 & & \\
\hline Lack of awareness & & & -.929 & \\
\hline $\begin{array}{l}\text { Lack of confidence in ability } \\
\text { to do physical activity }\end{array}$ & & & & .745 \\
\hline Poor physical health & & & & .726 \\
\hline \multicolumn{5}{|l|}{ Financial } \\
\hline \multicolumn{5}{|l|}{$\begin{array}{l}\text { Previous negative } \\
\text { experience }\end{array}$} \\
\hline \multicolumn{5}{|l|}{ Time } \\
\hline Eigenvalues & $3 \cdot 51$ & 1.49 & 1.17 & 1.09 \\
\hline$\%$ of variance & 31.93 & 13.51 & 10.6 & 9.9 \\
\hline Cronbach's $\alpha$ & .74 & .51 & $\mathrm{~N} / \mathrm{A}$ & .71 \\
\hline
\end{tabular}

Note. Only factor loadings higher than .512 are displayed. Unable to calculate Cronbach's $\alpha$ values for factor 3 due to single variable loading. 
Spearman's Rho was used to assess relationships between physical activity levels and the three factors. In the total sample $(N=105)$ and insufficiently active sample $(n=49)$, beliefs about physical capability was significantly, but negatively, related to physical activity levels. Negative beliefs about physical activity were positively correlated with physical activity in the total sample, whereas, poor mental health positively correlated with physical activity levels in the active sample $(n=56)$. A correlation matrix can be seen in Table 5 .

Table 5: Spearman's Rho Correlation Matrix of Factors and Physical Activity Levels

\begin{tabular}{l|l|l|l|l}
\hline & & $\begin{array}{l}\text { Poor Mental } \\
\text { Health }\end{array}$ & $\begin{array}{l}\text { Negative Beliefs } \\
\text { About Physical } \\
\text { Activity }\end{array}$ & $\begin{array}{l}\text { Beliefs About } \\
\text { Physical } \\
\text { Capability }\end{array}$ \\
\hline \multirow{3}{*}{$\begin{array}{l}\text { Physical } \\
\text { activity levels }\end{array}$} & Total sample & .13 & $.24^{*}$ & $-.51^{* *}$ \\
\cline { 2 - 5 } & Active sample & $.28^{*}$ & .06 & -.26 \\
\cline { 2 - 5 } & Insufficiently active sample & .14 & -.18 & $-.32^{*}$ \\
\hline
\end{tabular}

Note. ${ }^{* *}=$ significance $\leq .001 .^{*}=$ significance $\leq .05$.

Multiple regression revealed an unreliable model, with confidence intervals crossing zero; therefore, analyses are based upon correlation statistics.

\section{Perceived Benefits}

Mean scores of the perceived benefits relating to the total sample $(n=105)$, as well as values for male $(n=$ $80)$, female $(n=25)$, active $(n=56)$, and insufficiently active $(n=49)$ sub-groups are illustrated in Figure 3. Cronbach's $\alpha$ for all themes was $\geq .71$, suggesting adequate reliability. A principle axis factor analysis was conducted on the seven themes with oblique rotation (direct oblimin). However, no factors with eigenvalues over 1 were identified. This suggested that the themes did not measure the underlying constructs. Therefore, subsequent analyses employed mean theme scores.

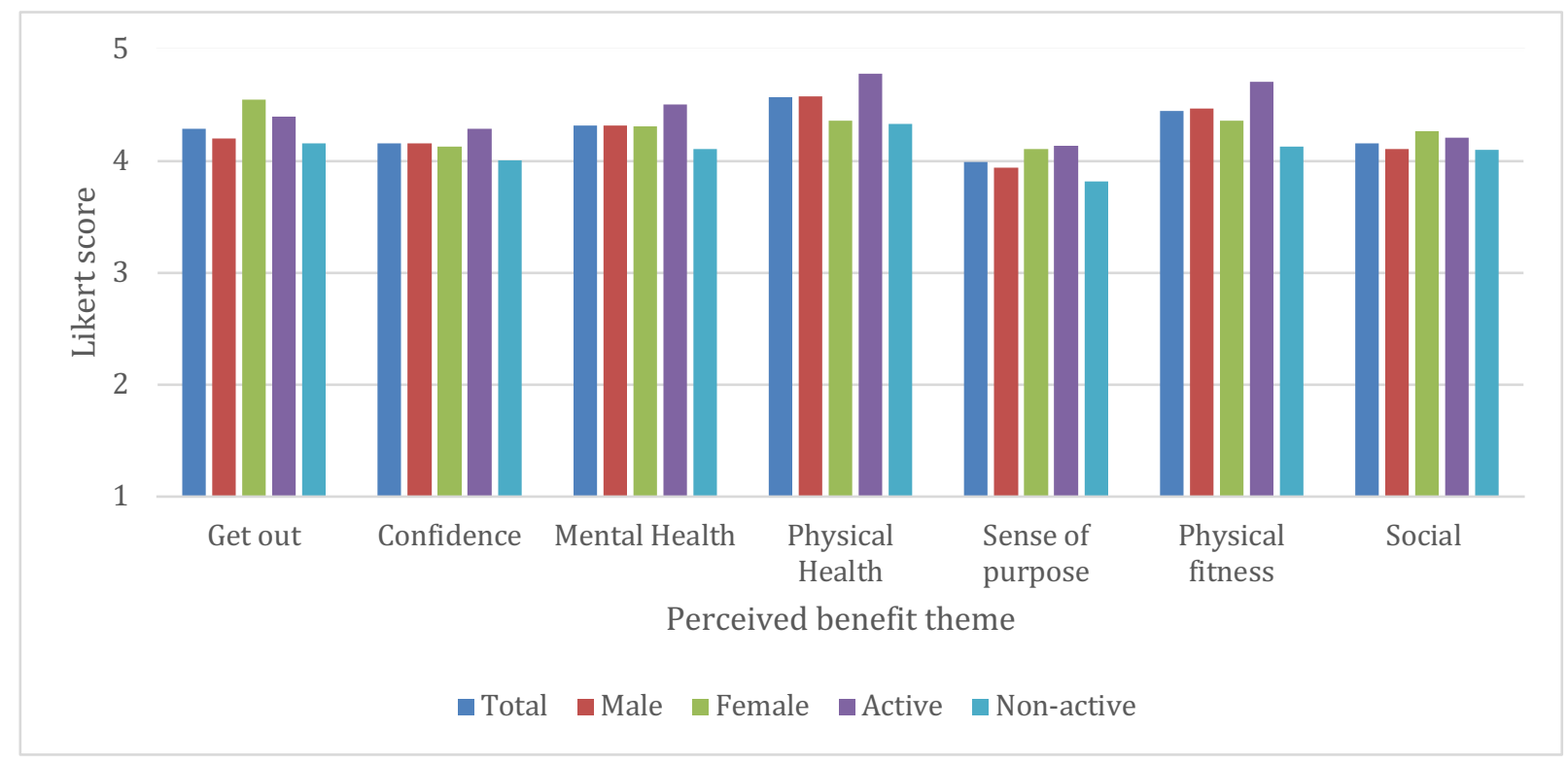

Figure 3: Mean Values of Perceived Benefits of Physical Activity for the Total Sample, Male, Female, Active, and Insufficiently Active Participants

Note. Higher scores represent higher reporting of each benefit. 
Perceived benefit scores did not differ significantly between male $(n=80)$ and female $(n=25)$ participants. However, active participants $(n=56)$ reported significantly higher beliefs that physical activity can improve confidence ( $U=1065, p=.04, r=.2)$, improve mental health $(U=975, p=.01, r=.26)$, improve physical health $(U=810.5, p=<.001, r=.38)$, give a sense of purpose $(U=1049, p=.04, r=.2)$, and improve physical fitness $(U=696.5, p=<.001, r=.43)$, than insufficiently active participants $(n=49)$.

Themes of increasing mental health, increasing physical health, sense of purpose, and increasing physical fitness held a significant positive relationship with physical activity levels in the total sample. However, as reported in Table 6, no significant relationships were identified among the insufficiently active or active sub-groups.

Table 6: Spearman's Rho Correlation Matrix of Perceived Benefits and Physical Activity Levels

\begin{tabular}{|c|c|c|c|c|c|c|c|c|}
\hline & & 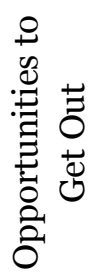 & 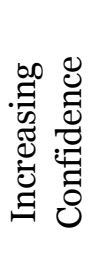 & 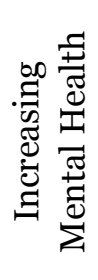 & 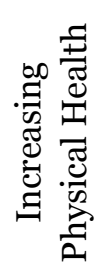 & 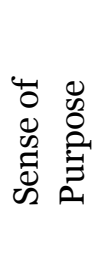 & 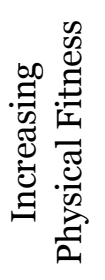 & 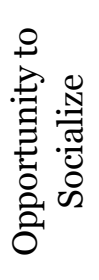 \\
\hline \multirow{3}{*}{$\begin{array}{l}\text { Physical } \\
\text { Activity } \\
\text { Levels }\end{array}$} & Total Sample & .18 & .18 & $.27^{* *}$ & $.37^{* *}$ & $.25^{*}$ & $.41^{* *}$ & .07 \\
\hline & $\begin{array}{c}\text { Active } \\
\text { Sample }\end{array}$ & .24 & -.01 & .13 & .15 & .16 & .14 & .05 \\
\hline & $\begin{array}{c}\text { Insufficiently } \\
\text { Active } \\
\text { Sample }\end{array}$ & .2 & .08 & .07 & .02 & .14 & .05 & .07 \\
\hline
\end{tabular}

Note. ${ }^{*}=$ significance $\leq .05 .{ }^{* *}=$ significance $\leq .01$.

The four themes identified as significant among the total sample in the correlation matrix were further analyzed using multiple regression. However, the 95\% bootstrapped CIs for three of the four themes crossed zero, suggesting an unreliable model. Consequently, this model has not been reported, thus inferences are based solely upon the correlation matrix.

\section{Discussion}

\section{Perceived Barriers to Physical Activity}

As hypothesized, unobserved, latent variables were identified from the questionnaire data, with four factors being extracted from the perceived barrier themes. However, only three of these factors were identifiable within the current study. A qualitative thematic analysis performed by Walker, Colclough, et al. (2020), identified the theme poor physical health, that was subsequently categorized as part of BCW COM-B category physical capability (See Figure 1), as participants reported that their physical health often reduced their ability to participate in physical activity (Walker, Colclough, et al., 2020). However, the factor analysis of the current quantitative study revealed that the themes poor physical health and lack of confidence in ability to do physical activity represented the same construct. This suggests that rather than an objective rating of physical health, this construct is more likely to represent beliefs surrounding physical health and its effect on perceived personal capability. 
Only beliefs about physical capability differed between males and females with respect to perceived barriers to, and benefits of, physical activity. However, the low effect size of this statistic would suggest that differences, if any, were minor. This finding provides important information as the exclusion of women from research linked to physical activity in veterans has resulted in a knowledge gap within existing literature (Shirazipour, Tennant, et al., 2019).

Separating the sample between active participants, those with a GSLTPAQ score of 24 or more, and insufficiently active participants, those with a GSLTPAQ score of 23 or less, identified a number of significant differences. Insufficiently active participants had a significantly lower belief in their physical capability. Moreover, beliefs about physical capability and physical activity levels held the strongest correlations between both the total sample and insufficiently active sub-group. This suggests that beliefs about personal physical capability represents a key barrier to physical activity engagement within the current study and that WIS veterans, with currently lower levels of physical activity, experience this barrier to a greater extent.

\section{Beliefs About Physical Capability and Physical Activity}

Beliefs about capability are often labeled as self-efficacy within the psychological literature (Bandura, 1997; Schunk \& DiBenedetto, 2020). A central component of social cognitive theory, one of the major theories of motivation, self-efficacy theory posits that those who feel efficacious are more likely to engage in cognitive and behavioral activities that improve their learning (Schunk \& DiBenedetto, 2020). Physical activity self-efficacy has consistently been shown to correlate with physical activity levels (Bauman et al., 2012; McAuley \& Blissmer, 2000), including among people with disabilities (Jaarsma \& Smith, 2018). Self-efficacy has also been shown to facilitate leisure time physical activity among people with disabilities (Martin Ginis et al., 2016), and has been used in the promotion of physical activity behavior among older veterans with PTSD (Hall et al., 2020).

According to qualitative research, low self-efficacy is a barrier to physical activity participation among veterans with lower limb loss (Littman et al., 2017). The findings of the current study build upon these previous qualitative findings. To the knowledge of the current authors, it provides the first quantitative association between physical activity levels and self-efficacy among WIS veterans.

\section{Perceived Benefits of Physical Activity}

Likely due to the small sample size of the active and insufficiently active sub-groups, perceived benefits only correlated with physical activity levels of the total sample. These included increasing physical fitness, increasing physical health, increasing mental health, and providing a sense of purpose; active participants expressed stronger belief in these benefits.

The belief that physical activity can have a positive impact on mental and physical health and provide a sense of purpose has been identified through qualitative methodology among WIS veterans (Walker, Colclough, et al., 2020) and veterans with a lower limb loss (Littman et al., 2017). Interestingly, however, the strongest association identified with physical activity levels was increasing physical fitness. While this has been identified by Walker, Colclough, et al. (2020), to the research team's knowledge, this is the first study that has identified a relationship between beliefs that physical activity can increase fitness and reported levels of physical activity among WIS veterans.

Outcome expectations of a behavior, such as the perceived benefits within the current study, is a determinant of the behavior according to both the BCW (Michie et al., 2014) and social cognitive theory (Bandura, 1997; Schunk \& DiBenedetto, 2020). Outcome expectations have been identified as a contributory factor to leisure time physical activity among people with disabilities (Martin Ginis et al., 2016). However, in their systematic review of reviews, Choi et al. (2017) suggested that self-efficacy was a stronger and clearer correlate of 
physical activity than outcome expectations. This mirrors the findings of the current study; that is, observed beliefs about physical capability are a stronger correlate of physical activity than all of the outcome expectations (i.e. perceived benefits). Therefore, while interventions targeting the outcome expectancies may be beneficial, researchers and practitioners may find targeting self-efficacy more effective in encouraging physical activity behavior change among WIS veterans.

\section{Behavior Change Wheel Implications}

COM-B Analysis. As a starting point to behavior change, the BCW recommends identifying what needs to change within the person and/or environment in order for the behavior change to occur (Michie et al., 2011, 2014), which is achieved through a COM-B analysis. The qualitative research on which the current study was based (Walker, Colclough, et al. 2020), was the first COM-B analysis to be performed with WIS veterans. However, due to the factor analysis reported above identifying latent variables within the themes outlined in the paper by Walker, Colclough, et al. (2020), a new COM-B analysis was appropriate. Reflective motivation and psychological capability categorized the three constructs of barriers to physical activity in the current study.

Reflective motivation describes reflective processes involving plans and evaluations (Michie et al., 2011, 2014). It can encompass many aspects of behavior, including identity, beliefs about capability/outcomes, optimism, intentions, and goals (Cane et al., 2012). Whereas, psychological capability characterizes knowledge or psychological skills, strength or stamina that are required to engage in the necessary mental processes (Michie et al., 2011, 2014).

The findings of the current study have significant implications in terms of a COM-B analysis. Specifically, the reduction of the original 11 perceived barrier themes into three factors identified the prominence of reflective motivation barriers among WIS veterans. This leads to important considerations in terms of designing behavioral interventions. For example, Walker, Colclough, et al. (2020) suggested that physical capability (i.e. poor physical health) was a prominent barrier to physical activity. To overcome this type of barrier, practitioners could provide adaptive equipment and suitable training to ensure its safe and correct use (Michie et al., 2011, 2014), thus increasing physical capability among this population. However, as identified in the current study, poor physical health represented the same factor as lack of confidence in ability to do physical activity, hence this is likely to describe perception/beliefs surrounding poor health, rather than an objective reality, and its impact on perceived capability. Thus, providing equipment may not be an appropriate strategy to overcoming barriers related to perceptions/beliefs. Table 7 presents a COM-B analysis of the factors identified in the current study.

Table 7: COM-B Analysis of the Perceived Barriers to Physical Activity Engagement Among WIS Veterans.

\begin{tabular}{|l|l|c|}
\hline \multicolumn{2}{|l|}{ COM-B component } & Perceived Barriers \\
\hline \multirow{2}{*}{ Capability } & Psychological & $\bullet$ \\
& Physical & \\
\hline \multirow{3}{*}{ Opportunity } & Physical & \\
\cline { 2 - 4 } & Social & \\
\hline & Automatic & \multicolumn{2}{|}{} \\
\cline { 2 - 4 } & Reflective & $\begin{array}{l}\text { Beliefs about physical capability } \\
\text { Negative beliefs about physical } \\
\text { activity }\end{array}$ \\
\hline
\end{tabular}


Walker et al., 2021

Due to the nature of perceived benefits, all were categorized as the beliefs about consequences TDF domain that has been mapped to the BCW (Cane et al., 2012). Consequently, all perceived benefits were categorized as reflective motivation.

Intervention Functions. The BCW provides a number of intervention functions that, following a COM-B analysis, can be used to facilitate behavior change (Michie et al., 2011, 2014). Based upon the results of the current study, future intervention designs may benefit from targeting reflective motivation among WIS veterans, as these appear to be most associated with physical activity levels. Michie et al. $(2011,2014)$ suggested that intervention functions that target reflective motivation barriers may include education, persuasion, incentivization, and coercion (See Figure 1). Although coercion in the form of a loss-framed financial incentive has been shown to improve daily step count among people with ischemic heart disease (Chokshi et al., 2018), coercion was not considered appropriate for WIS veterans due to their potential physical and mental vulnerability. Thus, respective intervention functions of education, persuasion, and incentivization are further discussed below.

Education. Greater levels of knowledge have been associated with greater levels of physical activity (Fredriksson et al., 2018), and education has been identified as playing an important role in leisure time physical activity among people with disabilities (Martin Ginis et al., 2016). Practitioners often use educational materials as a component of physical activity interventions (Cavallo et al., 2012; Krebs et al., 2020; Selzler et al., 2020), including those targeted at veterans (Ewert, 2014; Harrold et al., 2018; Townsend et al., 2018). A modeling-based video education intervention has been shown to increase exercise self-efficacy among a sample with chronic obstructive pulmonary disease (Selzler et al., 2020). However, the application of education in interventions often exists among several other interventional components, making it difficult to determine the extent to which education contributed to the success of each intervention. Nevertheless, education is considered an important facilitator of physical activity behavior among people with disabilities and can be used as an intervention function to overcome both psychological capability and reflective motivation (Michie et al., 2011, 2014). Both of these were identified as barriers to physical activity among WIS veterans in the current study.

Persuasion. Persuasion utilizes communication to induce positive or negative feelings or stimulate actions and can be used to overcome reflective motivation barriers (Michie et al., 2011, 2014). Persuasive technologies are commonly used with electronic devices, such as mobile applications, and have been shown to have a positive impact on physical activity behavior (Matthews et al., 2016). Persuasive technologies allow the selfmonitoring of physical activity behavior and can provide automated messages and feedback to prompt behavior change (Matthews et al., 2016). For example, Fitbit is a popular persuasive technology that targets physical activity behavior. In a technologically developing world, this form of persuasion may be a particularly useful intervention modality. In a veteran context, however, two recent RCTs of persuasive technology interventions did not observe increases in physical activity levels (Christiansen et al., 2020; Damschroder et al., 2020), with Damschroder et al. (2020) reporting challenges surrounding participant retention at a 12month follow up. However, a lack of statistical significance in these feasibility trials could be explained by their small sample sizes and, therefore, the application of persuasive technologies for veterans may warrant further investigation.

Motivational interviewing may also represent an effective method of persuasion. This approach employs a direct, client-centered counselling style used to elicit behavior change by helping clients explore and resolve matters of ambivalence (Miller \& Rollnick, 2012). A recent systematic review identified that the application of motivational interviewing positively impacted levels of motivation for physical activity (Nuss et al., 2020). While the application of motivational interviewing may involve more logistical considerations, compared to the automated persuasive technologies of mobile applications, practitioners may find benefit in its application to overcome the reflective motivational barriers of WIS veterans. 
Incentivization. Incentivization involves creating an expectation that a reward will follow the desired behavior and can be used for overcoming reflective motivational barriers (Michie et al., 2011, 2014). Incentives are useful to initiate behavior until the behavior itself becomes a rewarding incentive. This may be particularly important in the promotion of physical activity behavior among WIS veterans, as incentives may help overcome physical activity self-efficacy related barriers. Subsequently, according to self-efficacy theory, this barrier will subsequently reduce as the individual acquires performance accomplishments (Bandura, 1997; Schunk \& DiBenedetto, 2020), resulting in increased levels of physical activity.

Incentivization has seen application in the promotion of physical activity, showing signs of its positive impact on physical activity behavior (Ball et al., 2017; Finkelstein et al., 2016; Norman et al., 2016). In a veteran context, outdoor, nature-based physical activity interventions are often used for veterans with physical and mental health conditions (Greer \& Vin-Raviv, 2019; Shirazipour, Tennant, et al., 2019; Walker, Smith, et al., 2020). Such interventions, provided by charitable organizations, are usually free of charge and may provide an opportunity to conduct expensive outdoor activities that participants would otherwise find unaffordable. For example, physical activity interventions in the form of fly-fishing (Bennett et al., 2017), horse riding (Gehrke et al., 2018), and outdoor recreation-based health and wellness programs (Townsend et al., 2018) may, as activities in themselves, provide incentives to participate. Practitioners may find the use of such activity-based incentives beneficial in the promotion of physical activity among WIS veterans.

\section{Strengths, Limitations, and Future Research}

A key strength of this study lies in its design in relation to the BCW and COM-B model. The development of quantitative methods used were based upon findings of a previous, qualitative study, but the findings of the current study highlighted the importance of using larger, quantitative studies to explore the results of COM-B analyses stemming from qualitative data. The COM-B analyses of Walker, Colclough, et al. (2020) identified physical capability, psychological capability, physical opportunity, and reflective motivation as prominent categories of barriers. However, factor analysis made it possible to identify that these barriers represented latent variables that constituted a mixture of psychological capability and reflective motivational barriers, the latter of which significantly related to physical activity levels, which had subsequent implications for intervention design. For example, an intervention design based upon the COM-B analysis reported in Walker, Colclough, et al. (2020) may have resulted in a waste of resources, such as designing an intervention to overcome barriers that may not exist. This finding does not only apply in the field of physical activity behavior change, but suggests that the wider application of the BCW and COM-B related research may benefit from using quantitative methodologies, where possible, to confirm and further investigate the results of qualitative data.

A second strength of this study lies in the number of female participants that were included. Almost a quarter (23.8\%) of the sample included in this study was female, a proportion that reflects the male dominated gender ratio of UK military veterans, which is $12.5 \%$ female (Ministry of Defence, 2019). This is particularly important as Shirazipour, Tennant, et al. (2019) identified a lack of inclusion of women as a limitation in the existing literature.

Limitations of the study included the sample size, which was not able to meet the desired size of 220 participants based upon a medium effect. Despite the aid of a prominent military charity, recruiting larger numbers of such a specific group of participants proved challenging. Limitations related to statistical power have been noted in previous research surrounding veterans with health conditions and physical activity (Johnston et al., 2015; Shirazipour, Aiken, et al., 2019). Although such research may lack statistical power, vulnerable sub-populations are, by definition, small, and the avoidance of such research may create significant health disparities (Etz \& Arroyo, 2015). Moreover, data from the current study identified predominantly small 
effect sizes, suggesting that a sample larger than 220 may be required. Some statisticians advise a sample size of at least 300 for conducting exploratory factor analysis (Field, 2018). Despite this, the results of KMO testing suggested that, although this sample was relatively small, it was adequate for the factor analyses conducted (Stevens, 2002). However, the high number of active participants in this study may have biased results, thus, limiting their generalizability. Due to the small size of this sub-group, factor analysis was not conducted with insufficiently active participant data. Identifying a larger sample of insufficiently active veterans may be a useful direction for future research.

Another limitation may relate to the relatively few variables that loaded onto the three factors extracted. Although Raubenheimer (2004) recommended that a minimum of three variables should load onto a factor, questionnaires have previously been developed using two-variable loaded factors; for example, as in the BigFive Personality Domains Scale (Gosling et al., 2003). Within the current study, the research team considered that, despite the two factor loadings, there was sufficient evidence to support the two-variable loaded factors. Negative beliefs about physical activity have also been cited in the veteran physical activity literature, taking the form of lack of interest (Littman et al., 2014; Walker, Colclough, et al., 2020) and perceived hassle of activity (Littman et al., 2017). Similarly, beliefs about capability exist as barriers to physical activity among veterans (Littman et al., 2017; Walker, Colclough, et al., 2020). Therefore, loading factors 2 and 4 using two variables is justifiable.

Some may view the low reliability of the negative beliefs about physical activity factor as a limitation. However, despite low reliability, this factor was retained in subsequent analyses as it may be indicative of a useful direction for future research. Many statisticians recommend interpreting reliability scores within the context of the research area, and low Cronbach's $\alpha$ may be appropriate in new areas of research (Field, 2018), particularly as Cronbach's $\alpha$ values are positively related to the number of items on a scale (Cortina, 1993). Therefore, within the novel methodology of the current study, retaining this factor is justifiable, although further research is needed, and this finding should be interpreted with caution.

A further limitation involved the small number of BCW and COM-B model elements that were included in the questionnaire. Due to potential participant response fatigue, we limited the number of themes to those prominent in the findings of Walker, Colclough, et al. (2020). However, in order to develop a reliable, valid, and reusable questionnaire related to the perceived barriers and benefits of physical activity among WIS veterans, the exploration of additional aspects of the BCW and COM-B model is required.

Self-reported levels of physical activity may be another limitation of this study. Despite the use and application of GSLTPAQ in similar research in this field (Goldstein et al., 2018; Littman et al., 2014), the selfreport questionnaire may result in an inaccurate representation of participants' actual physical activity levels. Despite the GSLTPAQ being found reliable with maximum oxygen uptake and body fat in adults (Godin \& Shephard, 1985), recent research has identified longitudinal differences and weak associations between selfreported measures of physical activity, device measured physical activity, and sedentary behavior (Lines et al., 2020). Therefore, the application of device measured physical activity may provide a more accurate representation of participant physical activity levels. However, using devices to measure physical activity behavior, while desirable, was not feasible within the current study, nor would it be practical for some wheeled/adapted forms of physical activity.

Future research may benefit from expanding upon the questionnaire themes to identify a broader picture of physical activity behavior using a larger sample of WIS veterans. Despite its limitations, the current study and findings of other contemporary research in this area (Shirazipour et al., 2017; Shirazipour, Aiken, et al., 2019, 2018; Shirazipour \& Latimer-Cheung, 2020; Walker, Colclough, et al., 2020) provide practitioners with an initial understanding of physical activity behavior among veterans. This theoretical basis can be used to inform the development of a complex intervention, as recommended in the United Kingdom Medical Research Council's guidance (O'Cathain et al., 2019). In doing so, future practitioners may also benefit from 
adopting longitudinal randomized controlled trial design in order to overcome the limitations of contemporary physical activity interventional research noted in a recent systematic review (Walker, Smith, et al., 2020)

\section{Implications for Positive Social Change}

WIS veterans face significant challenges following discharge from military service. Ongoing physical and mental healthcare is key to ensuring wellbeing in veterans' post-military lives (Williamson et al., 2019). The results of the current study help further the understanding of physical activity behavior among WIS veterans, something that is increasingly being utilized to promote health and wellbeing in this population (Brittain \& Green, 2012). Considering these findings and recommendations for intervention design, practitioners can be better informed in the development of effective behavior change strategies that encourage physical activity behavior among WIS veterans. Numerous psychosocial benefits of physical activity have been identified in the literature, such as reductions in symptoms of PTSD and depression and improved confidence, quality of life, and social wellbeing (Caddick \& Smith, 2014; Shirazipour, Tennant, et al., 2019; Walker, Smith, et al., 2020). This suggests that engagement in these physical activity interventions will lead to many psychosocial health benefits, resulting in an improvement of wellbeing in this population. 
Walker et al., 2021

\section{References}

Adelson, J. L., \& McCoach, D. B. (2010). Measuring the mathematical attitudes of elementary students: The effects of a 4-point or 5-point Likert-type scale. Educational and Psychological Measurement, 7o(5), 796-807. https://doi.org/10.1177/0013164410366694

Amireault, S., \& Godin, G. (2015). The Godin-Shephard leisure-time physical activity questionnaire: Validity evidence supporting its use for classifying healthy adults into active and insufficiently active categories. Perceptual and Motor Skills, 120(2), 604-622. https://doi.org/10.2466/03.27.pms.120v19x7

Ball, K., Hunter, R. F., Maple, J. L., Moodie, M., Salmon, J., Ong, K. L., Stephens, L. D., Jackson, M., Crawford, D. (2017). Can an incentive-based intervention increase physical activity and reduce sitting among adults? The ACHIEVE (Active Choices IncEntiVE) feasibility study. International Journal of Behavioral Nutrition and Physical Activity, 14(1), 35. https://doi.org/10.1186/s12966-017-0490-2

Bandura, A. (1997). Self-efficacy: The exercise of control. Freeman.

Bauman, A. E., Reis, R. S., Sallis, J. F., Wells, J. C., Loos, R. J., \& Martin, B. W. (2012). Correlates of physical activity: Why are some people physically active and others not? The Lancet, 380(9838), 258-271. https://doi.org/10.1016/S0140-6736(12)60735-1

Bennett, J. L., Piatt, J. A., \& Van Puymbroeck, M. (2017). Outcomes of a therapeutic fly-fishing program for veterans with combat-related disabilities: A community-based rehabilitation initiative. Community Mental Health Journal, 53(7), 756-765. https://doi.org/10.1007/s10597-017-0124-9

Brittain, I., \& Green, S. (2012). Disability sport is going back to its roots: Rehabilitation of military personnel receiving sudden traumatic disabilities in the twenty-first century. Qualitative Research in Sport, Exercise and Health, 4(2), 244-264. https://doi.org/10.1080/2159676X.2012.68510O

Buis, L. R., Kotagal, L. V., Porcari, C. E., Rauch, S. A., Krein, S. L., \& Richardson, C. R. (2011). Physical activity in postdeployment Operation Iraqi Freedom/Operation Enduring Freedom veterans using Department of Veterans Affairs services. Journal of Rehabilitation Research \& Development, 48(8), 901-911. https://doi.org/10.1682/JRRD.2010.08.0144.

Caddick, N., \& Smith, B. (2014). The impact of sport and physical activity on the well-being of combat veterans: A systematic review. Psychology of Sport and Exercise, 15(1), 9-18. https://doi.org/10.1016/j.psychsport.2013.09.011

Cane, J., O'Connor, D., \& Michie, S. (2012). Validation of the theoretical domains framework for use in behaviour change and implementation research. Implementation Science, 7(1). https://doi.org/10.1186/1748-5908-7-37

Cavallo, D. N., Tate, D. F., Ries, A. V., Brown, J. D., DeVellis, R. F., \& Ammerman, A. S. (2012). A social media-based physical activity intervention: A randomized controlled trial. American Journal of Preventive Medicine, 43(5), 527-532. https://doi.org/10.1016/j.amepre.2012.07.019

Choi, J., Lee, M., Lee, J. K., Kang, D., \& Choi, J. Y. (2017). Correlates associated with participation in physical activity among adults: A systematic review of reviews and update. BMC Public Health, 17(1), 356. https://doi.org/10.1186/s12889-017-4255-2

Chokshi, N. P., Adusumalli, S., Small, D. S., Morris, A., Feingold, J., Ha, Y. P., Lynch, M. D., Rareshide, C. A., Hilbert, V., \& Patel, M. S. (2018). Loss-framed financial incentives and personalized goal-setting to increase physical activity among ischemic heart disease patients using wearable devices: The ACTIVE REWARD Randomized Trial. Journal of the American Heart Association, 7(12), 1-47. https://doi.org/10.1161/JAHA.118.009173 
Christiansen, C. L., Miller, M. J., Kline, P. W., Fields, T. T., Sullivan, W. J., Blatchford, P. J., \& StevensLapsley, J. E. (2020). Biobehavioral intervention targeting physical activity behavior change for older veterans after nontraumatic amputation: A randomized controlled trial. $P M \& R, 12(10), 957-966$. https://doi.org/10.1002/pmrj.12374

Cooper, L., Caddick, N., Godier, L., Cooper, A., \& Fossey, M. (2018). Transition from the military into civilian life: An exploration of cultural competence. Armed Forces \& Society, 44(1), 156-177. https://doi.org/10.1177/0095327X16675965

Cooper, L., Caddick, N., Godier, L., Cooper, A., Fossey, M., \& Engwarda, H. (2017). A model of military to civilian transition: Bourdieu in action. Journal of Military, Veteran and Family Health, 3(2). https://doi.org/10.3138/jmvfh.4301

Cortina, J. M. (1993). What is coefficient alpha? An examination of theory and applications. Journal of Applied Psychology, 78(1), 98. https://doi.org/10.1037/0021-9010.78.1.98

Damschroder, L. J., Buis, L. R., McCant, F. A., Kim, H. M., Evans, R., Oddone, E. Z., Bastian, L. A., Hooks, G., Kadri, R., White-Clark, C., Richardson, C. R. (2020). Effect of adding telephone-based brief coaching to an mhealth app (Stay Strong) for promoting physical activity among veterans: Randomized controlled trial. Journal of Medical Internet Research, 22(8), Article e19216. https://doi.org/10.2196/19216

Davies, P., Walker, A. E., \& Grimshaw, J. M. (2010). A systematic review of the use of theory in the design of guideline dissemination and implementation strategies and interpretation of the results of rigorous evaluations. Implementation Science, 5(1), 1-6. https://doi.org/10.1186/1748-5908-5-14

Department of Health and Social Care. (2019, September 7). UK Chief Medical Officers' Physical Activity Guidelines. https://assets.publishing.service.gov.uk/government/uploads/system/uploads/attachment data/file 1832868/uk-chief-medical-officers-physical-activity-guidelines.pdf

DeVellis, R. (2017). Scale development: Theory and applications (4th ed.). Sage.

Etz, K. E., \& Arroyo, J. A. (2015). Small sample research: Considerations beyond statistical power. Prevention Science, 16(7), 1033-1036. https://doi.org/10.1007/s11121-015-0585-4

Ewert, A. (2014). Military veterans and the use of adventure education experiences in natural environments for therapeutic outcomes. Ecopsychology, 6(3), 155-164. https://doi.org/10.1089/eco.2013.0035

Faul, F., Erdfelder, E., Lang, A.-G., \& Buchner, A. (2007). G*Power 3: A flexible statistical power analysis program for the social, behavioral, and biomedical sciences. Behavior Research Methods, 39, 175191. https://doi.org/10.3758/BF03193146

Field, A. (2018). Discovering statistics using IBM SPSS statistics (5th ed.). Sage Publications.

Finkelstein, E. A., Haaland, B. A., Bilger, M., Sahasranaman, A., Sloan, R. A., Nang, E. E., \& Evenson, K. R. (2016). Effectiveness of activity trackers with and without incentives to increase physical activity (TRIPPA): a randomised controlled trial. The Lancet Diabetes and Endocrinology, 4(12), 983-995. https://doi.org/10.1016/S2213-8587(16)30284-4

Fredriksson, S. V., Alley, S. J., Rebar, A. L., Hayman, M., Vandelanotte, C., \& Schoeppe, S. (2018). How are different levels of knowledge about physical activity associated with physical activity behaviour in Australian adults? PLoS One, 13(11), 1-10. https://doi.org/10.1371/journal.pone.0207003

Fulton, J. J., Calhoun, P. S., Wagner, H. R., Schry, A. R., Hair, L. P., Feeling, N., Elbogen, E., Beckham, J. C. (2015). The prevalence of post-traumatic stress disorder in Operation Enduring Freedom/Operation Iraqi Freedom (OEF/OIF) veterans: A meta-analysis. Journal of Anxiety Disorders, 31, 98-107. https://doi.org/10.1016/j.janxdis.2015.02.003 
Gehrke, E. K., Noquez, A. E., Ranke, P. L., \& Myers, M. P. (2018). Measuring the psychophysiological changes in combat veterans participating in an equine therapy program. Journal of Military, Veteran and Family Health, 4(1), 60-69. https://doi.org/10.3138/jmvfh.2017-0015

Godin, G. (2011). The Godin-Shephard leisure-time physical activity questionnaire. Health and Fitness Journal of Canada, 4(1), 18-22. https://doi.org/10.14288/hfjc.v4i1.82

Godin, G., \& Shephard, R. J. (1985). A simple method to assess exercise behavior in the community. Canadian Journal of Applied Sport Sciences, 10(3), 141-146.

Goldstein, L. A., Mehling, W. E., Metzler, T. J., Cohen, B. E., Barnes, D. E., Choucroun, G. J., Silver, A., Talbot, L. S., Maguen, S., Hlavin, J. A., Chesney, M. A. (2018). Veterans Group Exercise: A randomized pilot trial of an integrative exercise program for veterans with posttraumatic stress. Journal of Affective Disorders, 227, 345-352. https://doi.org/10.1016/j.jad.2017.11.002

Gosling, S. D., Rentfrow, P. J., \& Swann, W. B., Jr. (2003). A very brief measure of the Big-Five personality domains. Journal of Research in Personality, 37(6), 504-528. http://doi.org/10.1016/Soog26566(03)00046-1

Greer, M., \& Vin-Raviv, N. (2019). Outdoor-based therapeutic recreation programs among military veterans with posttraumatic stress disorder: Assessing the evidence. Military Behavioral Health, 1-18. https://doi.org/10.1080/21635781.2018.1543063

Hall, K. S., Morey, M. C., Bosworth, H. B., Beckham, J. C., Pebole, M. M., Sloane, R., \& Pieper, C. F. (2020). Pilot randomized controlled trial of exercise training for older veterans with PTSD. Journal of Behavioral Medicine, 43(4), 648-659. https://doi.org/10.1007/s10865-019-00073-w

Harrold, S. A., Libet, J., Pope, C., Lauerer, J. A., Johnson, E., \& Edlund, B. J. (2018). Increasing physical activity for veterans in the Mental Health Intensive Case Management Program: A community-based intervention. Perspectives in Psychiatric Care, 54(2), 266-273. https://doi.org/10.1111/ppc.12233

Hutcheson, G., \& Sofroniou, N. (1999). The multivariate social scientist. Sage Publications.

Jaarsma, E. A., \& Smith, B. (2018). Promoting physical activity for disabled people who are ready to become physically active: A systematic review. Psychology of Sport and Exercise, 37, 205-223. https://doi.org/10.1016/j.psychsport.2017.08.010

Johnston, J. M., Minami, T., Greenwald, D., Li, C., Reinhardt, K., \& Khalsa, S. B. (2015). Yoga for military service personnel with PTSD: A single arm study. Psychological Trauma: Theory, Research, Practice, and Policy, 7(6), 555. https://doi.org/10.1037/trao000051

Krebs, S., Wurst, R., Göhner, W., \& Fuchs, R. (2020, June 16). Effects of a workplace physical activity intervention on cognitive determinants of physical activity: A randomized controlled trial. Psychology \& Health, https://doi.org/10.1080/08870446.2020.1780233

Lines, R. L., Ntoumanis, N., Thøgersen-Ntoumani, C., McVeigh, J. A., Ducker, K. J., Fletcher, D., \& Gucciardi, D. F. (2020). Cross-sectional and longitudinal comparisons of self-reported and device-assessed physical activity and sedentary behaviour. Journal of Science and Medicine in Sport, 23(9), 831-835. https://doi.org/10.1016/j.jsams.2020.03.004

Littman, A. J., Bouldin, E. D., \& Haselkorn, J. K. (2017). This is your new normal: A qualitative study of barriers and facilitators to physical activity in veterans with lower extremity loss. Disability and Health Journal, 10(4), 600-606. https://doi.org/10.1016/j.dhjo.2017.03.004

Littman, A. J., Boyko, E. J., Thompson, M. L., Haselkorn, J. K., Sangeorzan, B. J., \& Arterburn, D. E. (2014). Physical activity barriers and enablers in older veterans with lower-limb amputation. Journal of Rehabilitation Research and Development, 51(6), 895-906. https://doi.org/10.1682/JRRD.2013.06.0152 
MacLean, M. B., Van Til, L., Thompson, J. M., Sweet, J., Poirier, A., Sudom, K., \& Pedlar, D. J. (2014). Postmilitary adjustment to civilian life: Potential risks and protective factors. Physical Therapy, 94(8), 1186-1195. https://doi.org/10.2522/ptj.20120107

Martin Ginis, K. A., Ma, J. K., Latimer-Cheung, A. E., \& Rimmer, J. H. (2016). A systematic review of review articles addressing factors related to physical activity participation among children and adults with physical disabilities. Health Psychology Review, 1O(4), 478-494. https://doi.org/10.1080/17437199.2016.1198240

Matthews, J., Win, K. T., Oinas-Kukkonen, H., \& Freeman, M. (2016). Persuasive technology in mobile applications promoting physical activity: A systematic review. Journal of Medical Systems, 4O(3), 113. https://doi.org/10.1007/s10916-015-0425-X

Maynard, C., Trivedi, R., Nelson, K., \& Fihn, S. D. (2018). Disability rating, age at death, and cause of death in US veterans with service-connected conditions. Military Medicine, 183(11-12), 371-376. https://doi.org/10.1093/milmed/usy040

McAuley, E., \& Blissmer, B. (2000). Self-efficacy determinants and consequences of physical activity. Exercise and Sport Sciences Reviews, 28(2), 85-88.

Michie, S., Atkins, L., \& West, R. (2014). The Behaviour Change Wheel: A guide to designing interventions. Silverback Publishing.

Michie, S., Van Stralen, M. M., \& West, R. (2011). The Behaviour Change Wheel: A new method for characterising and designing behaviour change interventions. Implementation Science, 6(1), 1-12. https://doi.org/10.1186/1748-5908-6-42

Miller, W. R., \& Rollnick, S. (2012). Motivational interviewing: Helping people change. Guilford Press.

Ministry of Defence. (2017). Veterans: Key facts. https://www.armedforcescovenant.gov.uk/wpcontent/uploads/2016/02/Veterans-Key-Facts.pdf

Ministry of Defence. (2019, January 10). Population projections: UK Armed Forces veterans residing in Great Britain, 2016 to 2028.

https://assets.publishing.service.gov.uk/government/uploads/system/uploads/attachment data/file /775151/20190107 Enclosure 1 Population_Projections _UK Armed_Forces Veterans residing in Great_Britain_-_2016 to 2028.pdf

Motl, R. W., McAuley, E., \& Klaren, R. (2014). Reliability of physical-activity measures over six months in adults with multiple sclerosis: Implications for designing behavioral interventions. Behavioral Medicine, 4O(1), 29-33. https://doi.org/10.1080/08964289.2013.821966

Munir, F., Biddle, S. J., Davies, M. J., Esliger, D., Gray, L. J., Jackson, B. R., O’Connell, S. E., Yates, T., \& Edwardson, C. L. (2018). Stand More AT Work (SMArT Work): Using the Behaviour Change Wheel to develop an intervention to reduce sitting time in the workplace. BMC Public Health, 18(1), 319. https://doi.org/10.1186/s12889-018-5187-1

Norman, G. J., Heltemes, K. J., Heck, D., \& Osmick, M. J. (2016). Employee use of a wireless physical activity tracker within two incentive designs at one company. Population Health Management, 19(2), 88-94. https://doi.org/10.1089/pop.2015.0030

Nuss, K., Moore, K., Nelson, T., \& Li, K. (2020). Effects of motivational interviewing and wearable fitness trackers on motivation and physical activity: A systematic review. American Journal of Health Promotion. https://doi.org/10.1177/0890117120939030

O'Cathain, A., Croot, L., Duncan, E., Rousseau, N., Sworn, K., Turner, K. M., Yardley, L., \& Hoddinott, P. (2019). Guidance on how to develop complex interventions to improve health and healthcare. BMJ Open, 9(8), e029954. https://doi.org/10.1136/bmjopen-2019-029954 
Preston, C. C., \& Colman, A. M. (2000). Optimal number of response categories in rating scales: Reliability, validity, discriminating power, and respondent preferences. Acta Psychologica, 104(1), 1-15. https://doi.org/10.1016/Soo01-6918(99)00050-5

Raubenheimer, J. (2004). An item selection procedure to maximize scale reliability and validity. SA Journal of Industrial Psychology, 3o(4), 59-64.https://doi.org/10.4102/sajip.v30i4.168

Sachdev, S. B., \& Verma, H. V. (2004). Relative importance of service quality dimensions: A multisectoral study. Journal of Services Research, 4(1), 93-116.

Schunk, D. H., \& DiBenedetto, M. K. (2020). Motivation and social cognitive theory. Contemporary Educational Psychology, 6o, 1-10. https://doi.org/10.1016/j.cedpsych.2019.101832

Selzler, A. M., Rodgers, W. M., Berry, T. R., \& Stickland, M. K. (2020). Coping versus mastery modeling intervention to enhance self-efficacy for exercise in patients with COPD. Behavioral Medicine, 46(1), 63-74. https://doi.org/10.1080/08964289.2018.1561411

Seppälä, T., Hankonen, N., Korkiakangas, E., Ruusuvuori, J., \& Laitinen, J. (2018). National policies for the promotion of physical activity and healthy nutrition in the workplace context: A behaviour change wheel guided content analysis of policy papers in Finland. BMC Public Health, 18(1), 87. https://doi.org/10.1186/s12889-017-4574-3

Shirazipour, C. H., \& Latimer-Cheung, A. E. (2020). Understanding quality participation: Exploring ideal physical activity outcomes for military veterans with a physical disability. Qualitative Research in Sport, Exercise and Health, 12(4), 563-578. https://doi.org/10.1080/2159676X.2019.1645037

Shirazipour, C. H., Aiken, A. B., \& Latimer-Cheung, A. E. (2018). Exploring strategies used to deliver physical activity experiences to veterans with a physical disability. Disability and Rehabilitation, $40(26)$, 3198-3205. https://doi.org/10.1080/09638288.2017.1377297

Shirazipour, C. H., Aiken, A. B., \& Latimer-Cheung, A. E. (2019). Quality physical activity experiences for military veterans with a physical disability: Exploring the relationship among program conditions, elements, and outcomes. Journal of Military, Veteran and Family Health, 5(1), 80-92. https://doi.org/10.3138/jmvfh.2018-0017

Shirazipour, C. H., Evans, M. B., Caddick, N., Smith, B. A., Ginis, K. A., \& Latimer-Cheung, A. E. (2017). Quality participation experiences in the physical activity domain: Perspectives of veterans with a physical disability. Psychology of Sport and Exercise, 29, 40-50. https://doi.org/10.1016/j.psychsport.2016.11.007

Shirazipour, C. H., Tennant, E. M., Aiken, A. B., \& Latimer-Cheung, A. E. (2019). Psychosocial aspects of physical activity participation for military personnel with illness and injury: A scoping review. Military Behavioral Health, 1-18. https://doi.org/10.1080/21635781.2019.1611508

Stevens, J. (2002). Applied multivariate statistics for the social sciences (4th ed.). Lawrence.

Taylor, N., Lawton, R., \& Conner, M. (2013). Development and initial validation of the determinants of physical activity questionnaire. International Journal of Behavioral Nutrition and Physical Activity, 1O(1), 74. https://doi.org/10.1186/1479-5868-10-74

Townsend, J., Hawkins, B. L., Bennett, J. L., Hoffman, J., Martin, T., Sotherden, E., \& Bridges, W. (2018). Preliminary long-term health outcomes associated with recreation-based health and wellness programs for injured service members. Cogent Psychology, 5(1), 1-17. https://doi.org/10.1080/23311908.2018.1444330

Walker, R. A., Smith, P. M., Limbert, C., \& Colclough, M. (2020). The psychosocial effects of physical activity on military veterans that are wounded, injured, and/or sick: A narrative synthesis systematic review 
of quantitative evidence. Military Behavioral Health, 8(3), 292-307.

https://doi.org/10.1080/21635781.2020.1746445

Walker, R., Colclough, M., Limbert, C., \& Smith, P. (2020). Perceived barriers to, and benefits of physical activity among British military veterans that are wounded, injured, and/or sick: A Behaviour Change Wheel perspective. Journal of Disability and Rehabilitation.

https://doi.org/10.1080/09638288.2020.1781940

Williamson, V., Diehle, J., Dunn, R., Jones, N., \& Greenberg, N. (2019). The impact of military service on health and well-being. Occupational Medicine, 69, 64-70. https://doi.org/10.1093/occmed/kqy139

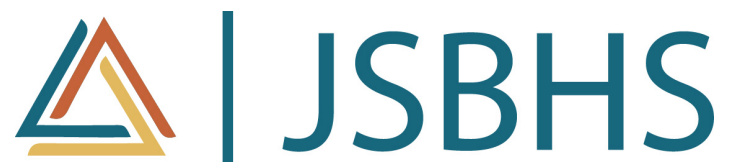

The Journal of Social, Behavioral, and Health Sciences (JSBHS), co-sponsored by the College of Health Sciences and the College of Social and Behavioral Sciences at Walden University, is a peer-reviewed, online, interdisciplinary journal focusing on theoretically-based research that addresses contemporary national and international issues. JSBHS articles include peer-reviewed research reports, brief reports, comprehensive literature reviews, book reviews, and student research. 